\title{
4. Aboriginal organisations and development: The structural context
}

\section{Robert Levitus}

In recent decades, the debate over mining development and Indigenous peoples has broadened, both geographically and thematically. The resistance paradigm that asserts the rights of communities against a new industrialised wave of dispossession has been sustained and applied to a succession of new case studies (Cultural Survival 2001; Downing et al. 2003; Hyndman 1994; Lane and Chase 1996; Roberts 1978). Alongside that, and especially in developed countries such as Australia and Canada, attention has shifted to work within a paradigm of engagement, negotiation and management (Howitt 2001: 208-65; Render 2005; Vachon and Toyne 1983). Much discussion now revolves around the achievement of best-practice processes to maximise the short and long-term benefits that mining can offer, and mitigate or compensate for the problems it causes (Hill 1999; Indigenous Support Services and ACIL Consulting (ISS/ACIL) 2001; O'Faircheallaigh 1996, 2003b; Sosa and Keenan 2001).

The most widely recognised benefit is the direct injection of earned income into the Indigenous domain, either by employment of Indigenous people in the mining operation or support for Indigenous businesses created to service the project (Cousins and Nieuwenhuysen 1984). A problem affecting both these economic inflows is their long-term sustainability, especially in the local area. Once the mining operation ceases, Aboriginal employees with skills and experience may be faced with a choice of returning to an environment of unemployment or underemployment, or moving to areas with an active job market. Similarly, businesses may have to fold or seek custom elsewhere.

A more indirect way in which mining companies have sought to transfer benefits to Indigenous communities is through the funding of local organisations which apply the received resources to various programs of their own design. In some cases these organisations' revenues will come in part from their role as business operators and thus face the same risk of mine closure. More importantly, however, mining agreements can direct substantial revenue flows, in the form of entitlements to an agreed percentage of mine income, to local organisations, allowing or even requiring them to accumulate capital funds over which they exercise long-term trusteeship. This is an important but under-utilised way in which mining companies can contribute to the preconditions for long-term remote-area Indigenous development that is not ancillary to the mining operation itself. 
Aboriginal organisations funded from mining revenue sit at the intersection of two policy discourses in Australia. The first is that adverted to already: that carried on within and around the mining industry itself about benefit packages for communities affected by mining operations. While also part of an ongoing national and international debate over social justice towards Indigenous people, this concern is internally motivated by increasing corporate recognition of the business case for preserving a social license to operate in remote areas where the population is often predominantly Indigenous. The second is the ongoing discourse around national policy in the area of Indigenous affairs. Within the paradigm of self-determination that had currency at the Federal level from the 1970s to the 1990s, Aboriginal organisations were strategically central. During those years also, the issue of the social license to operate came to the attention of some mining companies operating in Australia, so that the emerging industry attitude began to align with the national policy attitude. State government recalcitrance, especially in Queensland and Western Australia, and industry reaction, especially from the peak Australian Mining Industry Council (now Minerals Council of Australia), meant that this was never a uniform trend on either side. Moreover, the most recent phase of Federal Aboriginal policy-making ${ }^{1}$ has substantially abandoned the self-determination paradigm. Nevertheless the recognition of a form of native title in Australian law and a growing trend towards agreement-making have developed to sustain and expand the niches occupied by local Indigenous organisations, and the industry's preparedness to acknowledge their standing.

The purpose of this chapter is to consider Aboriginal organisations in their intended role as agents of development. It aims to identify a set of structural conditions under which they operate and which bear upon their capacity to implement development. My focus here thus falls within the paradigm of 'capacity building' that has attracted recent attention (Commonwealth of Australia 2004: 111-65). It is distinct from the common emphasis upon operational deficits in matters such as skills, knowledge and leadership suffered by many Indigenous organisations, but it does relate, especially in one of the later sections, to questions of governance. While the primary concern, consistent with the theme of this volume, is those organisations funded by mining revenue, they make up a small sub-set of Aboriginal organisations in Australia, and share the same general policy origins as the others. Thus, much of the following discussion has a wider focus. However, while the structural conditions that I identify are not unique to mining-funded organisations, I argue that several factors, including recent changes in the Indigenous affairs policy environment, cause these conditions to impinge upon such organisations in particular ways. Depending

\footnotetext{
${ }^{1}$ This is being written immediately following the election of November 2007 in which the conservative Liberal-National Party coalition was replaced by a Labor Government.
} 
on what share of their total resources are accounted for by mining, this has implications for their capacity to define a developmental path on behalf of their constituents.

After looking in the next section at the emergence of Aboriginal organisations in policy history, I discuss four structural conditions affecting their capacity to effect developmental change on behalf of an Aboriginal constituency. Central to this analysis is Charles Rowley's conceptualisation of Aboriginal organisations as a carapace. As such, they are simultaneously a transactional boundary and a point of articulation between external agencies and an Aboriginal domain. The structural conditions that I identify bear principally on these qualities. The first is the level of political authority at which the organisation articulates with its resource providers in the wider society, usually a state agency, sometimes a mining company. The second is the manner in which resources are transferred across that point of articulation into the jurisdiction of the Aboriginal organisation. The third is the availability of alternative sources of servicing and supply, independent of the organisation, to which its members or clientele may have resort. The fourth is the endogenous relationship between the organisation and the Aboriginal domain that it exists to service and/or represent. I then consider the particular position of organisations receiving funding from mining agreements with respect to these structural conditions. In the penultimate section, I discuss a central developmental function incumbent upon organisations located at this resourcing interface.

\section{The Aboriginal organisation in policy: carapace and domain}

The idea of corporatising the Aboriginal interest emerged from the progressive political thinking of the 1960s. Those corporate entities became a critical instrument through which the new policy paradigm of self-determination was to operate. Rowley, and like thinkers such as Strehlow (n.d.: 19-24) and Coombs (Rowse 2000a), argued for respecting the integrative values of the Aboriginal social group, and allowing room for Aboriginal group choice in implementing social change. They saw the Aboriginal domain as a basis for new forms of planning and action, as 'an opportunity for some real political science, ... for some real government' (Rowley 1966: 236). Rowley and Coombs wanted to admit the Aboriginal group as an agent of development, given an expanded conception of what development might mean. So the design of suitable forms of Aboriginal organisation and the fostering of an Indigenous leadership were strategically central to these policy reformers (Rowse 2000a: 31-3).

This was a decisive step in the field of Aboriginal development. Prior to this, Aborigines figured as welfare recipients or units of labour. Even where congregated as 'communities' on reserves, settlements and missions, Aborigines participated in the developmental programs of the assimilation era mainly as workers in internal servicing and primary production jobs, making sure that 
the structures of dependency were at least functional. The creation in the 1970s of Aboriginal councils and servicing agencies, and their recognition as an entry point for government moneys payable to those settlements, were intended to promote the conditions for self-determined development, that is, the endogenous determination of the future of those places as Aboriginal.

Self-determination thinking was open to the spread of such arrangements throughout Aboriginal Australia for almost any purpose relevant to local needs (Anderson 2004: 260; Commonwealth of Australia 2004: 111-12; Rowley 1972: 439-41). They were adopted even where Aborigines lived among whites, and the physical separateness characteristic of remote communities was absent. The adoption of the legally incorporated form across all areas of Aboriginal interest proceeded apace, so that from the mid-1970s many thousands of associations, services, centres, councils and corporations were registered under either the Commonwealth's Aboriginal Councils and Associations Act 1976, ${ }^{2}$ or corresponding State and Territory legislation. Rowse has written about this explosion of Aboriginal organisations across Australia as a central manifestation of the shift from assimilation to self-determination (Rowse 2000b: 1515-16; 2005: 214-19).

That policy step has consequently had major ramifications in the structuring of resource flows and political activity in all Aboriginal domains. The 'community', given legal personality by organisation into corporate forms, was deemed to be the initiator of development. From the perspective of the state, Aboriginal organisations were each a carapace beneath which the business of development could be allowed to proceed. These Indigenous legal entities thus carried the weight of the state's expectations that it could fund self-determining Aborigines to deliver development (see Batty 2005).

The two terms, domain and carapace, require comment. In his discussion of the concept of the Aboriginal domain, Rowse (1992: 19-21) substantiates it primarily in terms of content: Aboriginal people, using Aboriginal languages, organising themselves according to Aboriginal values for the pursuit of Aboriginal priorities. He also adverts to a criterion of size, but does not insist upon it, noting that some writers have applied the term to Aboriginal fields much smaller than, for example, the west Arnhem regional domain described by von Sturmer. Indeed Rowse distinguishes domain from 'enclave', a term he prefers to apply to such larger regions. The large-scale mining projects considered in this volume occur in regions where many Aboriginal people live in discrete settlements that would satisfy such a macro conception of the Aboriginal domain. Others, however, live in towns among white neighbours. Like Rowse, therefore, I do not wish to impose any requirement of size. Any arena in which affairs are consistently conducted

\footnotetext{
${ }^{2}$ Recently replaced by the Corporations (Aboriginal and Torres Strait Islander) Act 2006.
} 
in an Aboriginal idiom and informed by Aboriginal meanings, such that Aboriginal people expect such a mode of behaviour to occur there, is an instance of the Aboriginal domain.

In the last two decades, the concept of domain has been overtaken by new modes of conceptualising relations between the Indigenous and non-Indigenous in Australia (Hinkson and Smith 2005). I retain the concept here because it was central to the model of incorporation by which Rowley and his colleagues thought self-determination could be activated. Domain and carapace were the two structural halves of that model. In this chapter, inquiring into the activation of that model in the context of development, I want to ask how those constituent concepts fare in the face of what I argue to be the structural preconditions of such a role. In other words, we can judge the adaptability and durability of Rowley's conception by seeing how well it has meshed with those preconditions. Indeed, in such an analytical context, the concept of domain remains, in my view, a necessary tool for considering relations of articulation between collectivities. Moreover, the ethnographically minimal conception of domain being proposed here implies none of the hermetic or endogenously self-reproducing characteristics that have been the main cause for criticism of the concept.

Rowley $(1972: 423,429)$ conceived of the Aboriginal organisation as a carapace in the sense of a protective cover for the localised Aboriginal domain. My use here of the concept of carapace does not depend on the relationship between organisation and domain taking any particular ethnographic form, but rather arises from the positioning (and self-positioning) of organisations within policy. Later discussion will refigure the carapace as often more partial and fragmented than allowed by the initial vision of policy planners and intellectuals.

Viewed from the outside, it is clear that limitations upon the capacity of Aboriginal organisations to facilitate the self-determined development expected of them are implicit in the niche that has been created for them in public Aboriginal affairs. Historically, colonialism forged relations of articulation that now make Aboriginal society everywhere a part-society. To borrow a metaphor once prominent in anthropological theory, responsibility for the social reproduction of Aboriginal society is therefore nowhere located entirely within an Aboriginal social universe. It always draws to some extent on external sources of supply that are under non-Aboriginal control. This is so even in those remote areas where Indigenous domains are more socially self-contained. As discussed above, Aboriginal organisations are themselves an artefact of a particular moment in the policy management of those relations of articulation. They occupy niches created when the state decided that the points of articulation between Australian society and the various manifestations of Aboriginal part-societies that it encapsulates, should be made more permeable to Aboriginal participation and 
receptive to Aboriginal concerns. There they proliferated to a collective position of prominence.

As carapace, the Aboriginal organisation is an institution that creates a formal transactional boundary for certain purposes between its membership or clientele and the outside world. It is at the same time a conduit for external resources flowing into the Aboriginal domain. In the discussion that follows I want to look at that articulatory role and what it implies for Aboriginal development. The institutional boundary just referred to was seen to be essential if the development enabled by incoming resources was to be self-determined. The policy function of the organisational carapace as a point of articulation between Aboriginal and non-Aboriginal domains is thus central for realising self-determined development. There are at least two other structural conditions, however, that affect its potency in that respect. The first is the political level at which the point of articulation is established, and the second is the mode of transfer of resources from the non-Aboriginal domain.

\section{Condition 1: Political level of articulation}

The design of the carapace-the geographical area, functions, Aboriginal population and other organisations that it will encompass - has in past years been a major site of public debate over Aboriginal political futures. It seems that Rowley's (1972: 412-13, 424) initial conception presumed an organic correspondence between the organisation and the local Aboriginal group, and the Council for Aboriginal Affairs in the early 1970s similarly thought in terms of 'a politics of localised empowerments' (Rowse 2000a: 107-8). In time, political evolution and the legislative recognition of new rights at State, Territory and national levels produced correspondingly higher levels of Aboriginal organisation that typically discharged servicing and distributional responsibilities internally and lobbying and representative functions externally. Land councils and the Aboriginal and Torres Strait Islander Commission (ATSIC) have been the most familiar of these.

A domain of Indigenous control in the management of some resources intended for certain functions, is created beneath each such carapace. To that extent, the relationship between domain and organisation is reciprocal, such that the disposition of resources through the organisation tends to re-figure Aboriginal political relationships in reference to it (Martin and Finlayson 1996: 6-7; Sutton 1998: 69). Where the carapace exists at a high level of political aggregation, regional or larger, and other more localised organisations relate to that higher level as clients or constituents, that initial point of articulation with non-Aboriginal funding providers overlooks a geographically broad and internally differentiated Aboriginal domain of decision-making and service provision. 
The structures operating in the Northern Territory under the Aboriginal Land Rights (Northern Territory) Act 1976 (Cwlth) (ALRA) for distribution of moneys from resource developments on Aboriginal land, or those proposed by Pearson (2000a: 67-73) for a new model of governance in Cape York, are such instances. Smith (2002: 25-7) has proposed a model of jurisdictional devolution that she calls 'regionally-dispersed layered community governance', whereby major communities are conceived as bases of Indigenous authority and responsibility. They would then act 'as the starting point for aggregation at the sub-community and regional levels', servicing smaller satellite settlements, and being themselves aggregated for particular functions that are more effectively discharged at higher political levels. It seems clear, however, that any institutional arrangement established at a supra-community level would require its own funding entitlements from the state for stability and effectiveness, lest it fall away with each successive community secession. Thus the structural depth and geographical breadth of the Aboriginal domain depends in part on the vertical positioning of that linkage with the non-Aboriginal world that is made at the point of entry of external financial transfers.

\section{Condition 2: Mode of resource transfer}

The other important set of mechanisms affecting the jurisdictional power of the Aboriginal carapace relate to the manner of payment and extent of oversight of funds paid into the organisations concerned. In part this is the familiar issue of accountability. The application of external public funds to internal Indigenous programs places Aboriginal organisations in a mediating role between external accountability requirements and internal cultural conventions and proprieties over matters of access, distribution and control (Commonwealth of Australia 2004: 128-34; Macdonald 2004: 62-4; Martin and Finlayson 1996: 1-8). Much comment has recognised the difficulties that office-bearers and staff face in attempting to effect positive change in the face of multiple expectations that are both incompatible amongst themselves and unsympathetic to the overall operating environment (Austin-Broos 2003: 128; Sullivan 1996: 95-7; Thorburn 2006). The associated stresses may perpetuate the managerial dominance of relative outsiders who have nothing to lose but the job itself.

The complexity of both applying and accounting for external funds, and the weight this places on small organisations with limited skills, has been another difficulty. Such demands often leave no time for strategic planning, much less for the 'vision thing'. Pearson (1999: 33) criticises the 'hydra' character of government articulation with Cape York communities, of multiple parties and programs, and demands a more coordinated and holistic regional approach to resource use in which government plays a junior role (and see Gerritsen 1982: 18-19; Macdonald 2004: 44-5; Smith 2002: 6, but cf. Gray and Sanders 2006: 22-3, 25; Sanders 1993). A recent phase of policy innovation in Aboriginal affairs 
has emphasised coordination of agencies' programs across all functional areas through the Office of Indigenous Policy Coordination and a number of Indigenous Coordination Centres at the national and regional levels respectively (Office of Indigenous Policy Coordination 2004). The ideas behind these new structures are not entirely new (Gray and Sanders 2006: 19-21). Under the previous Labor Government for example, Daffen proposed that the Department of Administrative Services should take on just such a coordination role at national and community levels (Daffen 1995: 21-5, 39-51).

The complementary question is that of what scope Aboriginal organisations will be allowed to determine use of those moneys. The mode of transferring funds counts for much. I will distinguish here between block grants and pooled funding. By the former I mean a grant from a single funding source concerned with a particular functional area, such as health or education, in which the budget consists of one instead of many line items. The Aboriginal organisation is simply presented with, say, $\$ 5$ million for housing, rather than $\$ 5$ million divided into smaller amounts for particular structures, landscaping, fittings etc. The funds take the form of a single undifferentiated grant for unified Indigenous management and disbursement on housing needs. In that way, external transfers can, beneath that carapace, be converted into internal operational autonomy.

In its expansion across the country from the 1970s to the 1990s (Sanders 2005: 205-7), the Community Development Employment Projects (CDEP) scheme pioneered a new pattern of block grants in which the funds consolidated are not existing organisational grants, but individual welfare entitlements. By pooling unemployment benefits supplemented with amounts for capital and administration, these schemes place substantial resources at the disposal of Aboriginal management boards that function, generally, at about the suburban or municipal levels, and are able to mobilise the labour of between dozens and hundreds of local participants. At the time of writing, CDEP has passed through a phase of retraction under the policies of the Howard Government. Profitable settlement enterprises, especially general stores and alcohol canteens, offer, more indirectly and mostly at a smaller scale, the same potential. They can convert the transfers of government welfare payments to individual local Aborigines into a substantial retailing profit, some of which can similarly be made available for collective purposes such as airstrips or grants for education or ceremony (Arthur 1999: 7; Commonwealth of Australia 2000a: 90).

By pooled funding I mean the combining of allocations for a particular functional area from a number of funding sources, say a Commonwealth and its corresponding State/Territory department, into a joint payment, such as those disbursed by the Indigenous Housing Authority of the Northern Territory (Commonwealth of Australia 2000a: 65-6). Once again, the aim is to enhance self-determination by allowing a greater degree of internal operational autonomy 
(Smith 2002: 20-2). Such arrangements were trialed in the area of Indigenous health.

Under the trials each of the [Commonwealth, State and Territory] jurisdictions involved contributes an amount to the funds pool, based on an estimate of what would have been available to the community had there not been a trial. . . .

This pool of funds, which is no longer constrained by the specific rules of the programs of origin, can then be used by the community for service substitution and to address the health priorities that the community itself considers to be the most pressing.

The advantage of the trials is that there is much more intensive community involvement, both through consultation prior to the commencement of the trial and in the decision making on health services delivery during the course of the trial (Commonwealth of Australia 2000a: 30).

\section{Conditions 1 and 2: Articulation, aggregation and autonomy}

This mechanism has appeared particularly apt in company with the kind of vertical political development discussed previously. Prior to the abolition of the Federal-level ATSIC, a good deal of reformist thinking was focused on redesigning the political structures of Aboriginal affairs towards institutionalising Aboriginal authority at higher levels, and consolidating the revenues passing through those carapaces into Aboriginal domains at once larger and more functionally versatile. Reeves (1998), in his model for a new Aboriginal land rights regime, proposed a Northern Territory Aboriginal Council that would receive all royalties ${ }^{3}$ payable from resource developments on Aboriginal lands, to be disbursed through a competitive granting system to regional land councils, and then used to meet local needs for social or economic development.

Centralising the royalty stream would have required a proportion of it to be re-appropriated from existing local royalty associations. These bodies, and their individual members who in some cases receive cash distributions, would have no further direct entitlement (Reeves 1998: 361-3, 609). Reeves hoped that the vastly larger funds directed by ATSIC and Territory agencies into Aboriginal programs would be delivered the same way. Similarly, the Commonwealth Grants Commission raised the possibility of Indigenous-controlled State-level bodies through which all Commonwealth, and perhaps State, funding for Indigenous purposes would pass (Commonwealth of Australia 2000b: 59-60). Such a unified point of articulation in each State or Territory would constitute a single carapace

\footnotetext{
3 Strictly speaking, the moneys received by Aboriginal interests are royalty equivalents - that is an amount paid to them by government equal to the amount of royalties received by government.
} 
over what, it was argued, would be a more functionally integrated Indigenous domain.

Evident in some of these proposals, however, is a move beyond block and pooled funding to something in the nature of general revenue, in which there is a consolidation of funds from all sources, whether different agencies or levels of government, into a single sum, and no prescription even as to the 'portfolio' area to which the moneys are to be applied. As the terms used here imply, the degree of internal autonomy that this facilitates approaches the prerogatives of government. Pearson (1999, 2000a: 70-2, 78-80), operating at the regional level of Cape York, has argued explicitly that the political relationship between the Aboriginal and non-Aboriginal domains should be negotiated across an interface, in my terms a point of articulation, instituted at regional level, and across which resources should pass from the state with minimal regulation. As part of his campaign to convert 'negative' into 'positive' welfare, these resources should include those moneys currently being provided directly to individual Aborigines as pensions and benefits, thereby replicating the CDEP mechanism at a geographically and financially more inclusive level (Pearson 2000a: 88).

A further possibility arises from the work of Pretes (2005), who reviewed national and provincial-level trust arrangements in other parts of the world. These convert windfall or limited-term resource development payments into a permanent income-producing trust fund by means of investment in metropolitan capital markets. He reports that the tiny Pacific island country of Tuvalu entered an arrangement with aid donors for the advance payment of aid moneys into a trust, the income of which has largely removed the need for aid (Pretes 2005: 230-42). East Timor's Petroleum Fund is another example. Such arrangements have not been widely explored at the local or regional Aboriginal level, but they signal the possibility of a further step, from the device of converting external subsidy into internal operational autonomy, to transforming it into dedicated capital (eg. Altman 1985a: 143-5 and passim).

By progressively reducing the degree of prescription that accompanies external funding as it enters the Aboriginal domain, such institutional devices turn the organisational structure into a more absolute transactional boundary, and a more effective carapace. However, it is only necessary to recount these proposals of several years ago to be struck by how sharply they run against the more recent trend of policy. While that trend is now indeed towards program coordination and pooling of funds, developmental goals are to be negotiated between Indigenous interests and government, and progress towards those goals subject to official monitoring (Office of Indigenous Policy Coordination 2004). Innovations such as the health funding trials were among the last to explicitly endorse what was in effect a self-determination ethos at the level of local application. 
Following the abolition of ATSIC, renewed effort was directed at the coordination of administration and funding both between agencies and across levels of government in all areas of Indigenous servicing, as mentioned above. This 'whole of government' approach was combined, however, with a new assertiveness by Federal policy-makers insisting on the achievement of negotiated outcomes aimed at the improvement of conventional social indicators. This new attitude was proclaimed primarily by the highly publicised instrument of shared Responsibility Agreements, although they are supposed to cover discretionary funding only (Commonwealth of Australia 2005: 100-3; McCausland 2005a), and so far account for a tiny proportion of spending on Indigenous affairs (Gray and Sanders 2006: 13-14). ${ }^{4}$ Most recently, the Federal intervention in Northern Territory Aboriginal communities has dramatised government insistence on integration and public oversight as the path to acceptable outcomes in the policy arena of remote area Indigenous development. These initiatives were undertaken without reference to the major Northern Territory land councils. In other words, Aboriginal organisations are to become less of a transactional boundary, not more. The carapace is being removed.

\section{Condition 3: Alternative sources of supply}

Having considered up to this point structural conditions affecting the Aboriginal organisation in its relations with the external world of non-Aboriginal resource providers, I turn now to look at its relations with the Aboriginal domain that it services and represents. In this section I briefly discuss a third condition affecting the capacity of organisations to bring about self-determined development. This relates again to the extent to which an organisation is able to satisfy Rowley's image of the carapace, a protective layer that intercedes between the Aboriginal domain and the outside world, manages incoming traffic from non-Aboriginal agencies, and creates interior space for the formulation of Aboriginal priorities and responses. The limiting factor here is the availability of alternative service providers, and the scope that individuals and families from within the Aboriginal domain have, or seek, to conduct their affairs through alternative connections. The capacity of Aboriginal agencies to effect developmental change is dependent upon the relative intensity of their engagement with local Aboriginal affairs, with the daily functionality of Aboriginal lives, both in itself and by comparison with the Aboriginal business that passes them by. A comparison may help to make the point.

Remote area organisations seem best placed to maximise their share of dealings with Aborigines within their particular geographical and functional catchments. So, for example, when Pearson has made his arguments for a regional Cape York

4 Gray and Sanders (2006: 13) refer to 120 Shared Responsibility Agreements signed by November 2005. The government website < http://www.indigenous.gov.au/sra/search/srasearch.aspx > lists 267 as at December 2007. 
planning process that will take charge of all resources due to Aborigines from government and other parties, he then turns to the question of internal allocation for social and economic purposes beneath an Aboriginal organisational carapace that can claim almost comprehensive coverage of Aboriginal affairs on the settlements within that region. His proposals on this, as evidenced in his distinction between 'positive' and 'negative' welfare, are about changing the impact of existing resource inputs by managing them in a manner that promotes development instead of perpetuating dependency. Pearson's vision takes advantage of the conditions of remote Australia, where the lines of articulation connecting Aboriginal people on the ground with external servicing and welfare regimes, or to sources of supply in general, are limited in number, and therefore able to be negotiated and rationalised into a unified regional management structure. Perhaps the most ambitious instance of such a program was that attempted by the Indigenous Nodom and Pindan companies in the Pilbara in the 1940s and 1950s, in which company governance aimed to provide an exclusive regime of social control and development for all Aboriginal camp residents (Holcombe 2006: 7, 9, 11).

Turning to settled Australia, such possibilities for consolidated management are more limited, and were explored mainly at the local level through CDEP schemes, most now abolished. Whatever Aboriginal carapace can be constructed in the settled regions, it is always partial in both functional and geographical terms, existing alongside a multiplicity of non-Aboriginal agencies - shops, government offices, charities, employers, schools - through which Aboriginal people are able to conduct their affairs. The following passage describes the reach of Aboriginal organisational domains, and intersperses them with those mainstream domains accessed through Aboriginal linkage staff, in the small New South Wales country town of Walgett as listed by a member of a local Aboriginal family.

In the town there are several Aboriginal community services. ... Today the most central services are the Walgett Aboriginal Medical Service and the Aboriginal Lands Council. There are also Aboriginal employment services and schemes such as the Community Development Employment Program. Also important are Aboriginal education services and committees on three school campuses in the town . . . and the two Aboriginal Education Officers based at the Walgett branch of the NSW TAFE department. Walgett also has an Aboriginal Legal Service, several Aboriginal Health Workers and an Aboriginal Nurse at the Walgett District Hospital, Euragai Goondi which is a home for the elderly, operating also as a conference centre and accommodation service, Aboriginal Police Liaison Officers, Aboriginal Meals on Wheels workers, an Aboriginal community worker for the Department Of Community Services, three Aboriginal football teams, an Aboriginal Lawn Bowl team, and Aboriginal Cricket, Golf and Darts teams (Peters-Little 2000: 12-13). 
With the exception of rural property holdings, there is also no bounded or coherent physical domain. Aboriginal lives in settled Australia proceed in contiguity with an existing civic society. Aboriginal organisations, on the one hand, can offer only patchy coverage for people wishing to satisfy their needs by dealing with other Aborigines, and on the other hand, are less able to enforce social disciplines or participation in developmental programs. There are too many competing lines of articulation, which prevent the Aboriginal carapace in settled Australia from taking on the dimensions of broad civic authority that Pearson proposes for Cape York, and which allow its functional reach to be evaded.

That, indeed, is an explanation advanced by Sanders, Taylor and Ross (2000: 14-15) for the pattern of voter participation in ATSIC elections. Participation was highest in the remote ATSIC regions, lower in the southern settled regions, and lowest in capital city regions, because, they suggested, ATSIC resources became progressively less significant in each type of area as a proportion of total servicing resources and market opportunities available, and thus ATSIC was of correspondingly less importance in Indigenous peoples' lives. The same could be said of Aboriginal organisations in general. Conversely, in the remote Maningrida area of north Arnhem Land, the major improvement in infrastructure and amenities provided to the region's outstations by the local Aboriginal corporation was 'underwritten primarily by ATSIC in the 1990s' (Altman and Johnson 2000: 11). The contrast between remote and settled Australia thus suggests that the potential for an Indigenous model of development to emerge beneath the Aboriginal organisational carapace is inversely related to the extent of alternative individualised articulations maintained outside that carapace.

\section{Condition 4: Organisations and 'community'}

To this point, the ability of Aboriginal organisations to foster an Indigenous model of development has been discussed in terms of an interaction between their functions as a point of articulation and as carapace, that is, their capacity to operate as a transactional boundary within the policy and program structures of Aboriginal affairs. Other considerations emerge from looking beneath the carapace at the question of the internal coherence and integrity of the Aboriginal domains that they represent (Mantziaris and Martin 2000: 281-6). It directs our attention to endogenous constraints on developmental possibilities. As higher levels of organisation will inevitably comprehend more diverse constituencies, sometimes mutually hostile ones (Tonkinson 1984-5: 381), this question is sensibly pursued at the local scale.

Rowley appears to have regarded the relationship between community and organisation as unproblematic, perhaps organic. Sullivan, as evidenced by the title of his discussion paper 'A sacred land, a sovereign people, an Aboriginal corporation' (1997), similarly takes as fundamental the need for land-controlling 
organisations to faithfully embody a social community. The histories of many of the remote settlements for which formal incorporation was first conceived, as artificial clusters of traditionally separate and widespread groups, might have caused some prima facie reservations about the representative capacity of any single administration. Still, settlement councils and the like sprang from the realities of residence, and so could claim at least a secular municipal realism, if not a cultural authority (see Sullivan 1996: 10-12; Smith 2002: 23-4). The same can be said for some legal, health and other services that have been organised from the ground up in response to a localised Indigenous need. Holcombe (2004b) has gone further to describe how co-residence at a remote settlement can indeed provide a basis for the development of real communality among people of diverse traditional attachments.

In other cases, organisations have been created less as the incorporated form of a discrete pre-existing Indigenous domain and more as a contrivance around some connection between Indigenous space and an external contingency that happens to have policy relevance. Northern Territory royalty associations, for example, are constituted by s.35 of the ALRA around the accidental geography of a mineral deposit (Altman 1983: 126-30; Levitus 1991). Similarly accidental are the boundaries of land left available for transfer in various jurisdictions, but which make up an immutable frame within which Aborigines, whose attachments may extend into the land from different directions, must organise themselves as claimants, and then as owners and managers.

Policy initiatives, such as the devolved New South Wales local land councils, can be introduced into places in which colonial history has already embedded a potential for conflict between Indigenous groups. In many parts of Australia, both settled and remote (Macdonald 1997; Martin 1997; Pearson 2000a: 65), the localised distinctions between 'traditional' and 'historical' peoples structure internal Aboriginal conflicts that bear upon organisations and the disposition of their resources. Similarly, a different cultural consciousness and lack of mutual sympathy may divide town-dwelling 'half-castes' from reserve-dwelling 'blackfellas' (Sullivan 1996: 86-90). These common conditions of the political genesis of organisations condition also the ongoing character of political business conducted around and within them. Disputes among native title or land rights claimants, family politicking for capture of the resources of local organisations, disquiet over the introduced artificiality of 'communities' and the legitimacy of those deemed to be politically representative, all go to subvert any preconceptions of communitas beneath the carapace (Brennan 1998: 34-5; Macdonald 2004: 43; Mantziaris and Martin 2000: 277-80; Peters-Little 2000: 13-14, 17-21; Rowse 2000b: 1525). They therefore also bear upon any prospects for the endogenous mapping out of new paths of development. 


\section{Condition 4 (cont.): The political economy of organisation and domain}

We can, then, presume no necessary and natural dimensions of correspondence between Aboriginal groupings and Aboriginal organisations. However, recognising the potential for conflict and schism that resides in the historical or organisational overriding of Aboriginal diversity does not exhaust the issue. We can take it further by looking at two studies from the early 1980s that were not focused specifically on Aboriginal organisations, but posed alternative conceptions of the remote-area Aboriginal domain as an object of development policy.

Elspeth Young's (1981) portraits of the Northern Territory settlements of Yuendumu, Willowra and Numbulwar sought to forge a link between the recognition of development problems confined within economics, and the recognition of culture confined within anthropology. Young saw Aboriginal communities as a domain of difference. That difference affected both in degree and in kind their need for housing, health, education and employment, and affected also their capacity to derive benefit from the prevailing servicing regimes for all those things. Developing the Aboriginal economy demanded an understanding of that economy as Aborigines experienced it, including their understandings of money, commodities, welfare, land and business enterprise (for example, Young 1981: 162-4). Only on the basis of those levels of understanding could self-determination be realised. Young wanted policy to reform itself so that it could assist 'in bringing about the development of lifestyles closer to those which Aborigines desire' (1981: 3). Illustrative of her appreciation of Aboriginal lifestyle and thus of the internal character of the Aboriginal domain was her view of the implications of a shortage of cash at Yuendumu in 1978, when in one month only 41 per cent of adults received a significant monetary income.

Thus more than half of Aboriginal adults resident in Yuendumu have to depend on the generosity of their relatives and friends for money to buy food, clothing and other necessities. While the sharing of these resources is an integral part of the social system, vital to the maintenance of status and consolidation of alliances and relationships, the amount available for redistribution, as indicated by the low per capita income, is clearly less than required (Young 1981: 109).

Young thus interprets the management of this money shortage in the positive terms of cultural consolidation. It appears, however, to indicate major shifts in the politics of sharing. Subsistence resources were no longer sufficient for family needs, and access to them was rationed by controllers of vehicles, so the broad distribution of production rights and the balance of exchange linkages associated with that domain of bush provisioning were on the whole less significant for 
Yuendumu people. Cash income was now needed, but its distribution was substantially unbalanced. More than half the adult population was thus critically under-resourced for participation in the politics of reciprocity and patronage. Young's remarks suggest an intensive and unilateral deployment of kinship as a currency of supplication, which means that some people with money income were engaged in the constant tactical fielding of demands. We do not know to what extent this was burdensome or empowering (Austin-Broos 2003: 125-26; Peterson 1997: 190).

John von Sturmer studied the impact of major resource developments in western Arnhem Land from 1979 to 1983. He also saw difference, not in the sense of generalised cultural preferences, but as alternative sources and manifestations of power. He recognised how the social values contingent upon connections to country came to depend less on the shifting politics of access to increase sites and their bounty (von Sturmer 1984a), and more on the fixity of rights to mining sites and their royalties. He showed also how they had been joined by new structural points of control over resource flows into Oenpelli and Kakadu National Park. Von Sturmer (1984b: 151-63) thus probed the implications of self-determination policy and mining development in terms of the changing niches and rewards of employment and residence open to the Aborigines of western Arnhem Land.

The irony in this comparison lies in the relationship that each scholar perceives between Aboriginal agency and development. Young represents Aborigines as respondents of policy, and wants policy amended in ways that will allow Aborigines to respond to more desirable effect. Von Sturmer sees Aborigines as active calculators to whom policy presents opportunities for strategic emplacements leading to personal advantage (see also Gerritsen 1982: 21-6). Altman and Smith's (1994) subsequent study of the Nabarlek Traditional Owners Association clarified the anti-developmental outcomes implied by von Sturmer's analysis. Almost all moneys paid to local Aboriginal interests from the Nabarlek mine were disbursed in the form of vehicles and cash distributions, to beneficiaries determined more by personal networking than by traditional entitlement or social need. The amount devoted to social or financial investments that could produce lasting benefits was tiny. In contrast to Young, then, von Sturmer recognised not just a domain of difference, and not a moral economy, but an Aboriginal political economy.

These perspectives are relevant here for how they allow us to perceive Aboriginal organisations and the Indigenous domains that they overlook. Young's perspective acknowledges an Aboriginal desire for development of a culturally appropriate kind, but does not recognise internal differentiation in terms of the capacity of particular individuals or families to control traditional or introduced resources, and to interpolate themselves between those resources and other 
people who need them. Her perspective equips us to understand Aboriginal organisations that service such domains and claim to speak for them, in similarly opaque terms - that is according to their self-representation as facilitators of self-determined development. To that extent Young validates from the field the expectations of Rowley and Coombs as to the likely character of Aboriginal organisations as a policy intervention.

Von Sturmer's perspective makes us look at that policy intervention differently. By investing Aborigines with a political capacity and relating that capacity to new and old sources of power, he asks us to analyse the impact of the Aboriginal organisation in terms of structural innovation and the internal redistributions that flow from it. In other words, von Sturmer's approach points to a complementarity between the two policy functions of the Aboriginal organisation. As a point of articulation it channels material resources, and as a carapace it offers a set of political niches that are funded by, and positioned to take advantage of, that resource flow.

In addressing the relationship between Aboriginal organisations and domains, we therefore need to think in terms of a realpolitik of articulation. The picture is one of web-lines of major and minor fractures in the Aboriginal polity fanning out from every point at which resources feed in from the non-Aboriginal world. It requires us to place inverted commas around the word community, and offers a framework for understanding the excess of small-scale incorporations experienced in some areas (Commonwealth of Australia 2004: 130-31; Smith 2002: 9). It makes a matter for analysis the question of what new points of articulation and an enhanced flow of resources cause to happen among Aborigines and the implications of these things for development, and it moves such analysis beyond ethnic boundaries and the politics of difference to re-focus on older concerns like kinship, patronage, corporate groups and power (Austin-Broos 2003; Folds 2001: 144-7; Macdonald 2000: 106-9; Mantziaris and Martin 2000: 192-4; Smith 2005).

The implication here is that the policy conception of Aboriginal organisations as protagonists on behalf of an agreed community conception of welfare and progress must take cognisance of the standing of those organisations in relation to Aboriginal domains that are themselves political fields. These fields may include, it should be said, some political actors who genuinely seek to advance just such a common conception of welfare and progress. Thus, we need to remain open as well to the possibility that constructive organisational leadership can actually overcome family factionalism, as Pearson (2000a: 69-70) claims has occurred in the town of Coen, but that too must be a matter for analysis, and not accepted prima facie as a connotation of the term 'community'. 


\section{Aboriginal organisations and mining}

In a limited number of cases, a large proportion of the resources flowing to Aboriginal organisations come from agreements negotiated with resource developers. In such cases, that financial point of origin has implications for the way in which the four structural factors identified here bear upon those organisations.

The political level at which mining revenues enter the Aboriginal domain will depend on the legislative and institutional framework for managing them. In the Northern Territory, the formula given by the ALRA for distributing mining royalty equivalents from Aboriginal land for long directed the largest share (now somewhat reduced) to the Aboriginal land councils (Altman and Levitus 1999: 7-8). The two largest of these operate as high-level political and administrative organisations. In the 1980s Altman and Dillon (1988: 126) observed that

land councils represent the most advanced and comprehensive expression of Aboriginal self-government in the NT (and for that matter anywhere in Australia). Land councils' activities are increasingly para-governmental in nature.

That such a level of Indigenous political authority is funded from resource development is, of course, a peculiarity of the land rights legislation created for the Territory in the 1970s. Such an arrangement has not been replicated in other jurisdictions, and in its absence, the mining industry has found no reason of its own to fund Aboriginal interests at that level for anything beyond discrete projects of mutual concern. While mining companies may be international entities, their operating units are always local, and the business case for protecting their social license to operate by fostering Aboriginal development will be focused on Aboriginal groups in the areas affected by mining. Indeed, this local imperative is written into the Northern Territory legislation itself, under which traditional owners have veto rights over proposed exploration. Thus, the uranium company Energy Resources of Australia is legally required to deal with the Northern Land Council, but it has nurtured a relationship with the local Gundjehmi Aboriginal Corporation, the members of which are primary traditional owners of the Ranger and Jabiluka uranium deposits.

Even in the absence of a veto, hostile Aboriginal political action is bad both for its impact on public opinion towards the industry, and as a direct cost in the form of an impediment to land access or project continuity (Harvey 2002b: 4; Hawke and Gallagher 1989; Trebeck 2007a). For such reasons, mining companies will generally seek to concentrate resources flowing to Aboriginal interests at a local level. Consequently, and especially in a policy environment that has in recent years abandoned concern with high-level Aboriginal political development, the point of articulation across which resources flow from mine 
operators into Aboriginal domains will tend to be occupied by organisations constituted within limits that are proximate to the extraction project itself.

While that local focus is by definition a confining factor, the mode of transfer of resources into that domain can be relatively free. Altman and Dillon (1988: 134) comment that mining moneys in the Northern Territory 'from the Aboriginal perspective . . . are the single most significant source of finance that is untied and that can be used for development purposes'. Local associations established to represent people in the areas affected by mines on Aboriginal land are entitled to at least 30 per cent of the royalty equivalents payable from those mines.

Outside the Territory, Rio Tinto is pioneering a similar transfer of substantial resources to local Aboriginal control. In the East Kimberley, one of the criticisms directed by Aborigines at the notorious Glen Hill Agreement and the subsequent Good Neighbour Agreement entered into by the operators of the Argyle Diamond Mine in the 1980s was that the company controlled all moneys and decided what benefits were to be provided to the recipient communities (Dixon 1990). Moneys distributed by the Argyle Social Impact Group were similarly subject to non-Aboriginal criteria (Howitt 2001: 244-5). When the company moved into a new generation of community relations thinking and signed the Argyle Participation Agreement in 2004 (Harvey and Brereton 2005: 11), funding was directed to a number of community-controlled trusts.

In western Cape York, Comalco established the Weipa Aborigines Society in 1972 to carry out projects for Aboriginal benefit. Its lack of accountability to Aboriginal interests led to the creation of the locally operated Napranum Aboriginal Corporation in 1993, but corporate funding conditions continued to restrict the independence of that organisation as well (Howitt 2001: 220-2). Under the Western Cape Communities Co-existence Agreement negotiated between 1996 and 2001, a minimum of \$4 million annually is transferred from the company and the Queensland Government to the Western Cape Community Trust, under the majority control of local traditional owners (Harvey 2004: 241-42).

While such funding transfers under mining agreements are now less likely to allow for unrestrained and immediate consumption expenditure (Altman and Smith 1994; ISS/ACIL 2001: 37), to the extent that they are not accompanied by any specific spending prescription they preserve a potential for self-determined development. Such arrangements respect the status of the recipient organisations as a transactional boundary, and thus contrast with the ideological shift in the general Indigenous affairs policy environment represented by shared Responsibility Agreements. Indeed, Rio Tinto's senior Community and Aboriginal Relations officer was admonished by a public service bureaucrat that the relatively untied money provided by miners made the task of promoting Shared Responsibility Agreements more difficult for government (B. Harvey pers. 
comm.). Where government funding is increasingly tied to agreed outcomes, mining agreements may thus offer a preferred and relatively independent operating environment for Aboriginal organisations.

With respect to the third structural condition discussed above, that is the availability of alternative providers with which an Aboriginal organisation's constituency may prefer to conduct their affairs, the significance of mining revenues seems ambivalent. Those revenues, often being of the scale of a windfall for local Aborigines and relatively untied, can appear to present the promise of a coherent endogenous strategy of social development being designed and applied within a local Aboriginal domain beneath the protective coverage of a complete organisational carapace, much after the vision of the Nodom and Pindan companies mentioned earlier. Indeed the practice of substitution (whereby government agencies direct discretionary funding to communities without access to mining-related benefits and thereby force those groups funded by mining to use their income as a substitute for government servicing) can push onto such organisations a wider responsibility for local servicing than they may wish to have. But at the same time, major resource development projects in remote areas improve transport and communications and occasion the implanting of enclaves of western civil society alongside. In western Cape York, north-east and western Arnhem Land, the Pilbara and elsewhere, towns exist because of mining. The servicing agencies that populate these places can offer such a multiplicity of contacts to local Aborigines that their combined impact is not only confusing but anti-developmental, and their rationalisation has lately become a major priority in Indigenous policy (Edmunds 1989: 79-81; Gray and Sanders 2006).

Finally, the relationship between organisation and domain can be a particularly vexed feature of the structural context. I referred earlier to Northern Territory royalty associations as an example of organisations built upon an external contingency, their memberships determined by some process and politics of recognition of Aboriginal spatial relationships with the mine site. Any sizeable Aboriginal corporate entity will include categorical distinctions within its membership that can provide the raw material for political fission. Organisations that exist to receive benefits from a mine, however, would appear, by the absence of any 'natural' constituency and therefore of any original legitimacy, to be unusually predisposed to that risk.

I have elsewhere explored the impact of this failure of collective commitment in the history of the Gagudju Association of Kakadu National Park (Levitus 2005). Its replacement as the royalty-receiving association for the Ranger Uranium Mine by the Gundjehmi Aboriginal Corporation elevated narrowly conceived traditional rights over the mine site at the expense of a more expansive, though incoherently realised (Levitus 1991), concept of affected peoples. Similarly, the Rio Tinto officer mentioned above has remarked that one of the dangers for the 
company's policy of promoting regional Indigenous development in its areas of operation is the tendency in some circumstances for every clan and family to demand that the company pays for a lawyer to negotiate their own separate deal (B. Harvey pers. comm.).

In summary, then, the distinctive potential for sustainable and self-determined Aboriginal development offered by remote-area mining projects arises from their capacity to bring a large and relatively untied revenue flow to bear within a limited geographical range, through the agency of a locally constituted organisational structure. That potential, then, flows from the standing of such organisations with respect to the first two structural conditions discussed in this chapter. Perhaps that will not be enough. The record of the Gagudju Association suggests as much, for surely a local operational focus and active constituency and a large untied revenue flow were two of its strengths. Von Sturmer is one observer who requires more. The structural conditions that he listed for the success of west Arnhem royalty-receiving associations were akin to the third and fourth discussed here:

Success will hinge on their capacity to incorporate and to reflect all the features of Aboriginal social structure and organisation; to deflect fissive pressures; and to incorporate all other organisations operating within their sphere of influence within a single hierarchically-ordered structure; ... If they are to work, the associations must constitute literally a system of local government and be able to ensure social equity. They must be able to make rules, and to enforce them (von Sturmer 1982: 99-100-his emphases).

Clearly only some aspects of these specifications are controllable though negotiation and agreement with the miners. They evoke again the image of the complete carapace, and imply at least a political unity, if not Rowley's organic identity, between organisation and domain. Organisations established on this vision, even remote ones, will always be heir to the challenges of alternative external connections and internal differentiation.

\section{The assimilation of resources}

After acknowledging the structural limitations discussed so far, we need also to recognise the strategic centrality of Aboriginal organisations. This discussion has used two characterisations: each organisation occupies a point of articulation, that is, a bridge for the movement of resources across that intersection of policy and culture, and each is a carapace, marking out a functional framework beneath which a more-or-less coherent Aboriginal domain of action and values can be created, enhanced or preserved. As Rowley recognised in the beginning, that duality offers the potential, even within a context of dependency, to exercise some Aboriginal influence over processes of change. 
One important function that local Aboriginal organisations can have is to deflect and manage the impact of external subsidies upon Indigenous recipients. It is a function that has been most obviously and commonly exercised by CDEP schemes, that intervenes in the previously direct flow of money from social security providers into consumption expenditure by the clients, consolidate those multiple individuated flows into a resource and channel it through projects for community benefit. Northern Territory royalty associations illustrate other features of this intervening role. Royalty associations receive shares of the payments made from resource development projects under the ALRA. During the extended debate over reform of this legislation following the Reeves Report, the question arose as to whether there was any need to prescribe Aboriginal structures of decision-making below the level of a regional land council, that is, whether local royalty associations had any role to play. The view held by Reeves (1998: 207, 596) and others, that local traditional processes could be allowed free play, was in my view misconceived (Levitus 1999: 126-7). This issue goes to understanding the character of local organisations as, in the terms used above, a formal transactional boundary and a conduit for the transfer of resources, between the non-Aboriginal world and the organisations' memberships.

There are two important respects in which the allocatory tasks of local associations are different from those managed in pre-colonial times within traditional Aboriginal society. Firstly, the bundles of rights and benefits at stake are of enormous quantity by comparison with anything that passed through hunter-gatherer processes of production and distribution. The material values represented in a government instrumentality's one-line budget item, or in a single payment of mining royalty equivalents, is vast and unprecedented by comparison with the volume of desirables handled by traditional allocatory systems. Secondly, and perhaps more importantly, these benefits and entitlements do not physically originate from within the Indigenous domain, and so are not already enmeshed in those relationships of reciprocity and obligation that attach to locally produced items. Rather, they have an external source and are arbitrary both as to their timing and point of entry into the Indigenous system. They are unsocialised goods. So a program is approved and a delivery arrives - a housing project, a convoy of Toyotas, an office equipped with modern communication equipment - and local processes have to absorb it.

Because these items are so substantial, and management of them within the Indigenous domain is not already conditioned by relationships embedded within the circumstances of their production, it is necessary to design mediating structures and processes that function not to replace, but to assimilate them into, locally self-determined distributory mechanisms. That should be the function of royalty associations and like organisations. This connects with some of the concerns discussed above and with many of the considerations raised in discussions of governance and internal accountability (Dodson and Smith 2003; 
Hunt and Smith 2006b). It is complementary to the point made above, about the conversion of external subsidy into internal operational autonomy. That earlier point was about freeing resources from bureaucratic prescription and making them available to Aboriginal priorities. The present point is about subjecting those resources to a structured and considered passage into local Indigenous domains. Both matters need to be understood as preconditions to the implementation of Aboriginal development plans.

\section{Conclusion}

Aboriginal organisations were seen as an instrument through which a self-determined Aboriginal developmental trajectory could be formulated and pursued. They were an institutional home for what remained of policy's aspirations for Aboriginal development after that concept was surrendered into the discourse of self-determination in the 1970s. Their capacity to satisfy such aspirations can, from the outside, be seen to have depended on a number of structural conditions, operating both above, with respect to the supervening non-Aboriginal domain, and beneath, with respect to their own capacity as carapace. Those structural conditions, bearing upon the status of the organisation as a transactional boundary, continue to be a focus of policy innovation and discord. Most recently, the trend of policy has been to sidestep or overrule that boundary and project its managerial agency directly into local Aboriginal domains.

I have suggested here that Aboriginal organisations funded principally from mining projects are now relatively well placed to preserve internal operational autonomy. It is clear, despite the changing relationship between the mining industry and Indigenous people in Australia, that establishing and resourcing such organisations is not a widely acknowledged channel for transferring benefits to Aboriginal peoples affected by mining. The Australian Government's 'Working in Partnership' program for developing cooperative relationships between the mining industry and Indigenous communities heavily emphasises training, employment and business development. A ready possible explanation for this flows directly from my previous point. Government is more interested in promoting the mainstreaming linkages of employment and ancillary business between projects and local communities than in resourcing self-determination. Alternatively it may simply reflect a reasonable up-front emphasis on the immediate opportunities for project participation, relegating post-project sustainability to downstream planning.

There also seems to be limited industry recognition. Few of the companies subscribing to the Working in Partnership program provide revenue streams to local organisations under majority Indigenous direction. Indeed, of those mine sites surveyed by the Australian Bureau of Agricultural and Resource Economics that were located in the vicinity of a discrete Indigenous community, half had 
no agreements of any kind with local Indigenous people at the mining stage of their operations (Tedesco, Fainstein and Hogan 2003: 24). In another survey published in 2001, a highly disproportionate number of agreements between mining companies and Indigenous communities were attributable to only two companies, Rio Tinto and Normandy (ISS/ACIL 2001: 15). However, 'payments or other compensation mechanisms' was the most common kind of provision included in the 140 agreements surveyed, covering 'lump sum payments, soft loans, royalty equivalents, and equity in companies, rents and lease payments' (ISS/ACIL 2001: 17). Not all of these will produce a revenue stream for a locally-controlled Aboriginal organisation, but this figure provides an indication of a potential to be explored. These survey data suggest that few players are including the resourcing of Aboriginal organisations and post-mining development within their range of expectations from the advent of mining, but those players are important ones.

In the long-run history of any remote Aboriginal town facing deteriorating demographic trends (Taylor Chapter 3), the duration of even a major mining project is only a window (Render 2005: 35). Moreover, there will always be many people of working age in such areas who will never achieve the required state of work-readiness, or who have no wish to work in a mine, or who are numerically beyond the capacity of the mining industry to absorb them. In the relationship between mining companies and local Aboriginal populations, the resources and capacities of Aboriginal organisations will be an important determinant of the long-term developmental legacy a mining project will leave behind. The initiatives of such organisations will be a critical mediator between the windfall revenues from mining, and what those revenues are able to create and sustain for the Aborigines in that area. While the remote-area mining industry in Australia is currently undergoing unprecedented expansion, and there will always be major new projects eventuating here and there, for any given Aboriginal community the particular project occurring in their vicinity may be the only opportunity in much more than a generation to acquire the capital base for at least a partially self-resourced future. As O'Faircheallaigh remarks, 'a community will tend to have just one chance to extract revenue; if it fails in relation to this specific project, it fails in total' (1996: 198).

We leave the discussion, then, at the point where it begins to broach another issue, that is, the kind of development that Indigenous peoples may wish to foster. In the international discourse around the relationship between miners and indigenes, some have begun distinguishing between economic development and what is variously called culturally appropriate, community-led, or human, development, thinking less about how to fit Indigenous peoples into a commercial mining operation, and looking instead at how a commercial mining operation can fit into Indigenous life' (Render 2005: 35-8). This not only raises new questions of definition and evaluation, but places responsibility on 


\begin{abstract}
Aborigines themselves to determine what development should be, and how to bring it about. In this context, the matters discussed in this chapter are structural preconditions, important because they affect the ability of Indigenous interests to equip themselves with the institutional instruments necessary for development with or without mining. They are about using the resource transfer instigated by mining to create a space in which they may consider their own options for development. The work of development itself has still to follow.
\end{abstract}

